Revista de la red interuniversitaria de estudios sobre las literaturas rioplatenses contemporáneas en Francia

Hors-série | 2019

Ricardo Piglia: Cierta idea de literatura

\title{
Complot y teoría: lo que vino después (sobre los diarios editados de Ricardo Piglia)
}

\section{Graciela Montaldo}

\section{OpenEdition}

\section{Journals}

Edición electrónica

URL: http://journals.openedition.org/lirico/7885

DOI: 10.4000/lirico.7885

ISSN: 2262-8339

Editor

Réseau interuniversitaire d'étude des littératures contemporaines du Río de la Plata

\section{Referencia electrónica}

Graciela Montaldo, « Complot y teoría: lo que vino después (sobre los diarios editados de Ricardo Piglia) », Cuadernos LIRICO [En línea], Hors-série | 2019, Puesto en línea el 11 febrero 2019, consultado el 09 mayo 2019. URL : http://journals.openedition.org/lirico/7885; DOI : 10.4000/lirico.7885

Este documento fue generado automáticamente el 9 mayo 2019.

\section{cc) $(1) \ominus$}

Cuadernos LIRICO está distribuido bajo una Licencia Creative Commons Atribución-NoComercialSinDerivar 4.0 Internacional. 


\title{
Complot y teoría: lo que vino después (sobre los diarios editados de Ricardo Piglia)
}

\author{
Graciela Montaldo
}

1 La frase contundente y constantemente reiterada de Osvaldo Lamborghini, "Primero publicar, después escribir" (1988: 89), citada en ocasión de muy diversas experiencias pero eficaz y a la moda, logra darle la mejor forma conceptual -ante todo porque se construye como boutade- a algo que algunos escritores estaban experimentando ya a comienzos de los años setenta en la ciudad de Buenos Aires y que hoy vemos como una suerte de verdad profesional ${ }^{1}$. La frase, de algún modo, dejó de ser una boutade para convertirse en la declaración de un estado de cosas algo ominoso sobre el estado de la literatura en el presente. En el pasado presagiaba cambios difíciles de predecir. Ricardo Piglia menciona a Lamborghini en sus diarios -en el segundo volumen más precisamenteen muy pocas ocasiones $y$, en general, lo hace para describir a un joven escritor (o aspirante a), un entrometido en el mundo literario, que quiere ganar fama a costa de la tranquilidad y el prestigio de los demás. No le cae bien y, obviamente, jamás cita "su" frase, escrita y popularizada mucho después de que compartieran el espacio intelectual. Sin embargo, a veces no es necesario encontrar la prueba literal para establecer cierta convergencia; creo que ambos escritores forman parte de una experiencia de resignificación de la idea de escritor, de literatura y de la manera de enfrentar un nuevo lugar para los escritores y para las prácticas estéticas en un sentido más amplio. Algo que comenzó en los setenta y se estableció en el presente. Es claro que los dos piensan al "escritor" de manera diferente, pero se conectan allí donde surge la incomodidad frente al campo literario. Lamborghini tomará una vía algo espectacular, Piglia una mucho más privada. 


\section{Teoría}

2 En 2017 se completó la publicación de la trilogía de una selección y edición de los diarios de Ricardo Piglia, llamada Los diarios de Emilio Renzi. El desplazamiento del nombre (de autor) es muy básico, es simple, diríamos (Piglia ya había usado "Renzi" -su apellido materno- como nombre de personaje escritor) pero, en su sencillez, introduce el cambio que le permite pasar de la primera a la tercera persona, del pasado al presente, del registro a la ficción. Creo que resulta bastante claro que la condición de mito de esa escritura de registro reside, en parte, en su carácter de archivo (como el que aparece en el interior de los diarios repetidamente, el que acarrea su abuelo desde Italia, durante toda su vida, con las cartas de la guerra). Es un archivo tanto material (porque contiene la historia en los cuadernos) como inmaterial (porque son una edición y reescritura digitalizada, mediada por la transcripción). Piglia comenzó a escribirlos en 1957 pero quizás ninguna de sus escrituras parece más contemporánea por la superposición de tiempos de edición. Este carácter nos inclina hoy a leer estos tres últimos libros como "la obra" de Piglia, aquella que, durante décadas, inédita y como mito de escritura y de la formación del escritor, fue la forma de sustentar la idea de que el autor era un escritor y que, una vez publicada, arrincona todo lo que escribió y publicó antes a otra categoría, no la de obra escrita y publicada, sino la de los pretextos (en su doble sentido) de aquello que está por venir, y que anuncia lo que vino después de la literatura, de la obra, todo aquello que fue necesario escribir para ocultar el verdadero deseo de ser escritor. Porque los diarios recogen el deseo de volverse escritor pero no el escritor público sino el privado, no el escritor que escribe sino el que quiere escribir.

3 Todo esto lo deja en claro Piglia a lo largo de los tres volúmenes en entradas en las que una y otra vez subraya el uso de la escritura del diario como el verdadero laboratorio de "la literatura". Reflexiones sobre escritores, experiencias de lectura, posibles argumentos de futuros cuentos y novelas (muchos), publicaciones, revistas, ensayos, premios literarios, reuniones con otros escritores, trabajos de edición, traducciones, reseñas y, siempre, la pregunta por cómo volverse escritor. Junto con algunos pocos hechos de la vida cotidiana, éstas parecen ser las grandes preocupaciones de los diarios que reescribe en el siglo XXI. Piglia dice en el primer volumen, hablando de sus cuadernos:

Supongo que tendré alguna vez tiempo para rehacer estos cuadernos, recuperar el ritmo de estos años que se me filtra entre las manos. En definitiva, si no hay nada más que los diarios, podrán ser vistos como el proyecto de alguien que primero decide ser escritor y luego empieza a escribir, antes que nada, una serie de cuadernos en los que registra su fidelidad a esa posición imaginaria (2015: 323, énfasis mío).

Más argumentada teóricamente, la frase recoge la idea de una precedencia de la voluntad de escribir antes de que la literatura exista (incluso a pesar de ella) y también la convicción de que la "obra" pública/publicada ha dejado de ser lo relevante en un escritor (y sólo en esto se contacta con Lamborghini), que verdaderamente lo es cuando puede identificarse como tal, escriba o no, publique o no. Para Piglia, un escritor es siempre un escritor privado y su obra es autónoma de su figura.

5 En Piglia, el escritor es siempre el escritor de sus diarios, renegando de aquel "otro" (en el sentido borgiano) que publica, gana dinero (o no) y premios con la literatura. Si bien la publicación no forma parte de su declaración de identidad, sin embargo, aparece en los diarios de modos diferentes. Una de esas formulaciones tempranas es fundamental: 
El primer libro es el único que importa, tiene la forma de un rito de iniciación, un pasaje, un cruce de un lado al otro. La importancia del asunto es meramente privada pero nunca se puede olvidar, estoy seguro, la emoción de ver por primera vez un libro impreso con lo que uno ha escrito. Después, hay que tratar de no convertirse en "un escritor" (2015: 329-330).

Con la frase anticlimática final, Piglia parece afirmar que publicar es, de este modo, el proceso inverso a la consagración de la identidad. Si ser escritor es una actividad privada, el riesgo de publicar es adoptar la imagen pública, ser un escritor público, es decir, profesional.

7 No podríamos decir que Piglia estime los absolutos, ni siquiera el literario. Pero llama la atención el subrayado énfasis en lo que llama "la literatura" como algo que está más allá de todo lo que se escribe y publica, algo que se desea y que solo se logra en una intimidad donde no opera la ecología crítica de editores, reseñistas, jurados de premios, traductores. Por eso resulta relevante que se afirme que los diarios no son la literatura, los ensayos que escribe no son la literatura, las clases que enseña con éxito no son la literatura (recordemos que estudió historia, precisamente, para poder dedicarse a la literatura); tampoco lo son los argumentos literarios. Todo en su actividad de escritor parece un desvío de la literatura. Pero entonces, ¿qué es la literatura para Piglia? Partiré de esta pregunta sin respuesta precisa para explorar cómo la insistencia en formularla le permite hacerse cargo de la incomodidad con que los jóvenes escritores de la época se enfrentan a la literatura, una práctica ligada a la tradición y a una tradición elitista pero aún cargada de promesas emancipatorias, repolitizada en los muchos intentos experimentales, vanguardistas, en que Piglia y muchos otros jóvenes escritores estaban involucrados por entonces. Me interesa explorar qué representa la práctica burguesa de la literatura para estos escritores involucrados con el marxismo, la revolución y el psicoanálisis. Si bien es muy claro que Los diarios de Emilio Renzi hablan una y otra vez sobre la forma en que alguien se vuelve escritor, quisiera pensar que, en ellos, el gran tema es ¿qué es la literatura?, cuando todos creen saber bien qué es pero muchos sospechan que ya no lo saben, lo que podía ser un problema en una época en que las definiciones eran aún necesarias (baste recordar los libros y las polémicas en torno a Jean-Paul Sartre o, localmente, en torno a David Viñas).

8 Creo que los diarios vienen a mostrar la exploración del propio Piglia sobre las nuevas posibilidades de la literatura. Se interrogan por la práctica de la literatura en el momento en que se está produciendo un cambio en su concepción. En Los diarios... vamos a encontrar todo aquello que él terminó desarrollando en su ficción: el uso de los géneros y sus posibles mezclas, las citas, pero también la emergencia de "la vida" como material de la escritura y la problematización del "yo", todos los desplazamientos gramaticales de la ficción y el documento, lo que Piglia llamará "el archivo". Y, sobre todo, vamos a ver cómo escribir los diarios resulta en un ejercicio de exploración de los acontecimientos de "la vida" como material de ensayo del funcionamiento de la ficción. Pero también se desarrolla la reflexión sobre la literatura y sus procedimientos, porque un escritor, para Piglia, sí tiene derecho -y debe- hablar en términos conceptuales. Así lo escribe en una entrada del jueves 29 de enero de 1981: "Terreno inexplorado (en el muy agotado campo de la investigación literaria): el aporte de los escritores a la teoría y la reflexión sobre la literatura. Un escritor no tiene nada que decir sobre su propia obra, pero tiene mucho que decir sobre la literatura" (2017: 136). Y lo había escrito unos días antes, al sostener que "Cuando escribo ficción leo menos literatura, o mejor, cada vez que escribo me alejo más de la "literatura", pero, sin embargo, mi vida está escandida ("programada") por la 
escritura literaria" (119). En los diarios, Piglia se inscribe en una genealogía. Y vale la pena recordar que la escritura de los diarios está muy lejos de ser la transcripción de los 327 cuadernos que fue escribiendo entre 1957 y 2016 y que se trata de una escritura claramente editada, en donde no sólo alterna la primera y la tercera persona sino que acumula tiempos de escritura diversos en varias entradas de los diarios ${ }^{2}$, como dijimos. Ese espesor temporal complejiza también las ideas de obra, vida y, naturalmente, la de literatura.

Volviendo a esos jóvenes de los años setenta, fue evidente que ellos se colocaron enfrente del territorio ocupado por los escritores del boom, pues aquellos fueron grandes figuras públicas, pero antepusieron el valor de su obra a la hora de mostrarse (exhibirse podríamos decir) como escritores ${ }^{3}$; más allá de las declaraciones políticas de aquellos años, aquellos escritores defendieron una "concepción burguesa" de la literatura. Todos recordarán los ejemplos de Cortázar y García Márquez (por no mencionar la actualización decadente de Vargas Llosa), que se autorizaban a hablar de temas variados (especialmente de política) porque había una obra que los avalaba, que les permitía hacer públicas sus opiniones. No era el caso de Lamborghini, ni de Piglia, ni de tantos otros escritores jóvenes que, por lo demás, estaban poco interesados en dar opiniones sobre los acontecimientos históricos. Los jóvenes escritores que ponen énfasis en la idea de ser escritor y, especialmente, en la voluntad de ser escritor, retoman una nueva forma de la vanguardia. Es el caso de Lamborghini practicando una escritura experimental, y el de Piglia desarrollando una literatura que acompaña sus reflexiones sobre la vanguardia y leyendo la vanguardia en la literatura argentina en particular, pero, ante todo, redefiniendo la relación de "la literatura" con "la vida".

Por eso sus diarios, indagando sobre la literatura, indagan también un aspecto de lo que podríamos llamar la obra-Piglia que la edición de su escritura personal viene a subrayar: la relación de su escritura con la vanguardia. Si hablo de vanguardia es en el sentido más conceptual posible del término. Y me concentro en la relación, explorada por Andreas Huyssen ${ }^{4}$, entre vanguardia y cultura de masas. Desde la progresiva consolidación de la estética moderna, algunas obras y algunos autores ensayaron formas de revuelta a la lógica del consumo y a la de su institucionalización en el sistema del arte. Esas formas críticas se llamaron obras malditas, bohemia, vanguardia, neo-vanguardia, experimentalismo, y se caracterizaron por una profunda autorreflexión de los procesos estéticos, por un lado, y por una continua problematización de la relación del arte con la política, en la que se encontraba un modelo de crítica, resistencia y, finalmente, de ideal revolucionario desde el cual operar contra la lógica del consumo y la cultura de masas. Desde Flaubert (por poner un momento clásico) en adelante, la lucha contra el "filisteísmo" habla de la figuración de un enemigo que el arte se propone combatir, creando así una nueva forma de humanismo elitista contra la masividad del consumo. Esa contradicción básica (en contra de lo masivo, a favor de la emancipación) define buena parte del arte moderno más vanguardista y experimental y expone también la relación con el mercado. Abolidos los vínculos que ligaban a la literatura a lógicas externas a ella misma, se la dejó librada al orden propio del arte, como si quedara confinada a una sola lógica, la de la institución. Fue, sin duda, la ventaja que el arte moderno celebró en primera instancia, pero también a la que quedó condenado y reducido. Imposible preverlo a fines del siglo XIX, las derivas mismas del cuestionamiento estético llevaron a que la inserción institucional fuera ocupando cada vez más espacio en la conciencia de las obras. Reflexión, auto-reflexión, impusieron a la literatura y el arte un exilio definitivo de la 
espontaneidad o incluso de la relación consigo misma. Pero también le permitieron seguir sosteniendo los privilegios de lo estético en el mundo que iba a ser dominado por la cultura de masas.

11 La interacción ambigua de esas obras con el sistema del arte (pertenecer, pero críticamente, a él) las convierte en objetos en los que es posible leer controversias de la política moderna y el lugar que la cultura ocupó dentro de los debates por la emancipación. Es aquí donde la literatura y el arte se intersectan con lo que, en términos generales, llamo "teoría". Entiendo aquí la teoría como una práctica reflexiva sobre las condiciones de supervivencia del arte cuando está amenazado tanto por el consumo como por su propia destrucción (lo sepa o no, lo diga o no); entiendo la teoría como una práctica autorreflexiva que el arte y la literatura llevan a cabo para comprenderse a sí mismos y reflexionar sobre sus vínculos sociales. Entiendo la teoría como una suerte de preservación ante el consumo y la masificación de la sociedad del espectáculo. De manera paradójica, la "resistencia" que esta práctica generó no fue hacia lo social ni lo político, sino que recayó sobre la institución misma. Si la crítica (literaria, de arte) surge como una forma de mediación entre el artista/la obra y el público, la teoría emerge como un discurso y una práctica que se hace cargo de las transformaciones del arte moderno. Y lo hace no tanto mirando al público como a la propia institución estética. La teoría está completamente ligada a la progresiva institucionalización del arte y funciona como parte de ella. Y forma parte del proceso de autorreflexión que se impuso desde entonces.

12 La literatura de Piglia está inscrita en esta genealogía al punto de que muchas de sus ficciones pueden considerarse "ficciones teóricas". Pero esa dimensión teórica vanguardista- y conceptual está tramada por la experiencia personal. En Los diarios de Emilio Renzi Piglia trabaja la emergencia de "la vida" como material de la escritura. Hoy, en las estéticas contemporáneas, esta cualidad parece natural, pero Piglia lo venía trabajando desde temprano. Su primer libro publicado (Jaulario, que gana una mención en el premio Casa de las Américas, en la Cuba efervescente de la revolución) se publica en 1967. Ese mismo año ya tiene muy avanzada la antología de textos autobiográficos argentinos que publicará la editorial Tiempo Contemporáneo en 1968 y que se titula, precisamente, Yo. Uno de sus primeros libros, entonces, lleva el pronombre "yo" como única palabra del título, es un libro que él no ha escrito, pero que ha editado, como si allí mismo, en el minimalismo del título, fuera posible experimentar con el procedimiento que medio siglo más tarde usará en los diarios de Renzi, es decir, una primera persona que siempre es derivativa, esquiva y, sobre todo, engañosa, que encubre antes que exhibe y que grita "yo" cuando en realidad se apropia de escrituras ajenas. Esos libros se entraman con la escritura de los diarios. En el fragmento "Quién dice yo", del primer volumen de los Diarios, leemos: "Como nos ha enseñado la lingüística, el Yo es, de todos los signos del lenguaje, el más difícil de manejar, es el último que adquiere el niño y el primero que pierde el afásico. A medio camino entre los dos, el escritor ha adquirido la costumbre de hablar de sí mismo como si se tratara de otro" (2015: 336).

13 Estas mediaciones teóricas cuando se enuncia en primera persona ponen en evidencia que "la vida" en Piglia no es una categoría transparente. "La vida" no son los hechos, no son los sentimientos, no es la subjetividad ni las experiencias (personales o sociales). La vida parece ser el lugar donde se ejerce la ficción, el disparador de las tramas, los géneros, la experimentación con la lengua, las conexiones; el cruce de los dispositivos de la escritura. El dictum vanguardista de llevar la vida al arte es lo opuesto a la versión literal (si esto fuera posible) de esa aspiración. Poco sabremos de la vida de quien escribe los diarios, 
pero al leerlos, sí sabemos de qué modo la vida y la literatura se conectan, cómo una relación afectiva se puede convertir, por ejemplo, en una experiencia policial, de qué modo un amigo del escritor -un ladrón de guante blanco- puede introducir alteraciones (por sustracción) en el mundo real que operan como secretos, por qué una alucinación puede convertirse en un complot político. En lugar de pensar la literatura como aquello que le da una forma a la experiencia (la definición moderna de la ficción), en Piglia parece ser la vida la que informa a la literatura, la que le enseña cómo narrar y cómo narrarse. Pero no por similitud o imitación sino por lo contrario: porque la literatura aprende de las formas de la experiencia vivida una forma de la verdad. Por eso quizás, cuando Renzi reflexiona sobre los episodios de la novela familiar puede decir que:

Luego, cuando los retomo y vuelvo a contarlos, los argumentos cambian, no tienen nada de autobiográficos, pero nunca podría escribir un relato que no tuviera en el fondo una experiencia propia. Sin eso, dijo, sin un rastro de mi vida, no se puede narrar, o al menos yo no puedo creer lo que cuento si no estoy personalmente implicado (2015: 341-342).

Esta manera de leer la vida, de introducirla en la literatura para que ilumine la ficción, se hace visible en muchas secciones del diario. Tomaré una escena del primer volumen. El protagonista de la acción es Renzi, que tiene una suerte de romance con una chica pelirroja. Es muy joven, es el año 1960, está estudiando la carrera de Historia en La Plata. Como sabemos, muchos datos se superponen con la vida del mismo Piglia, pero aquí se produce el primer desplazamiento: la vida entra a la ficción. Por esos años, Renzi ya comenzó a escribir sus diarios, aunque no sabe bien el rumbo que van a tomar; también en esos años de juventud sabe que lo que más quiere es ser escritor y ya empezó a escribir cuentos. En un acto de seducción, le pasa a la chica de pelo colorado el cuaderno con sus relatos, para que ella los lea durante las vacaciones de invierno. Pero se equivoca, le da "por error" un cuaderno que contiene parte de su diario. Anota Emilio en la entrada del jueves 30 de junio:

Son mis lamentos por y con Lidia del año 59. [...] Me espanta la sola idea de que ella pueda estar leyéndolos en este momento. [...] Lo más chistoso es que estoy atrapado. No puedo decirle "dame mi diario, que te lo di por error". Lo mejor sería decirle que el diario es una novela y hacerme el indiferente respecto a su opinión. Está escrito en primera persona pero no creo que en ningún lugar haya puesto $\mathrm{mi}$ nombre. No creo haber escrito "Emilio fue para acá o para allá."

Tampoco puedo esperar a que lo lea y se me aparezca en la Facultad y me diga "éstos no son tus apuntes"; yo podría decirle "son los apuntes, pero de otra cosa". También imagino una situación en la que ella me dice: "No. No sé leer. Soy ciega. No entiendo castellano. Me lo olvidé en el colectivo. No tuve tiempo de abrirlo. Te amo. Este cuaderno demuestra que sos el hombre que yo estaba buscando". Lo vende, se va a publicar por entregas en el diario El Día de La Plata (2015: 82).

15 Cuando el escritor monta esta escena no parece querer contarnos simplemente un acontecimiento. La angustia (también la diversión) por haber cometido un error en el que quedará expuesto a la posible burla, la equivocación tan obvia de entregar un cuaderno en lugar de otro, disparan inmediatamente la literatura, formas de posibles ficciones; su amiga se convierte en un personaje que actúa de diferentes modos, su relación con Lidia en una trama policial, "la vida" se convierte en un folletín del diario El Día. Es un episodio, ficcional él mismo, en la medida en que "le pasa" a Emilio Renzi. Pero ¿qué más ficción que los cambios nominales y pronominales? ¿Qué más ficción que el armado de una trama para explicar su literatura? Por eso el diario sostiene que: "Esa cualidad única de estar adentro y fuera de una historia, y verla mientras sucede, marcó toda mi literatura y definió mi manera de narrar" (2015: 342). Pero la trama que une vida y literatura es más 
densa todavía; podemos recordar el fascinante análisis que hace Piglia de los diarios de Franz Kafka en El último lector (2005), espejo de la relación amorosa que relata en sus diarios y que acabo de citar. Allí dice: "Este procedimiento de relacionar "por caminos extraviados" lo que ha vivido con lo que ha escrito, percibir fragmentos de la realidad cifrados en los textos, es una de las claves del efecto Kafka" (2005: 52). Y agrega que "La clave es cómo lee Kafka su propio relato, qué lee allí. [...] La clave es que para entender y establecer la conexión hay que narrar otra historia, estar afuera" (2005: 54). Adentro y afuera conforman así los ritmos de creación de la literatura, una colocación imposible pero que habilita la ficción.

\section{Complot}

16 La vanguardia en la que Piglia se inscribe compromete a la vida, pero no sólo a ella. Los textos se vuelven su campo de batalla y, en el caso de Piglia, eso atraviesa toda su escritura. Pero es en Teoría del complot (2007) donde alcanza un punto de inflexión. Allí Piglia lee la literatura moderna como la historia de un complot, lee el arte (de vanguardia) como una forma de conspiración; una acción contra el Estado, contra la ley. Macedonio Fernández, Roberto Arlt, Jorge L. Borges, Witold Gombrowicz, forman la vanguardia de una ficción que se comporta como un proceso pre-revolucionario. Los escritores -dice Piglia-, los experimentales, los vanguardistas, se comportan como, y realmente son, una especie de agentes dobles, espías en territorio enemigo. Ese artista es el que, formando parte de la vida social, opera contra ella; insertado en las redes comunitarias y políticas actúa para quebrarlas, aniquilarlas. No se trata de que el artista sea un actor político tradicional. Por el contrario, es un camuflado, alguien que siempre tiene una doble vida. Por eso no se puede confiar en él, pero a la vez es inevitable participar en ese mundo, precisamente, porque uno es "escritor". De este modo, aunque a veces entra en el mundo de la farándula literaria, lo hace de manera irónica. Por ejemplo, el 13 de febrero de 1967, Piglia/Renzi recibe un telegrama a las ocho de la mañana diciendo que su obra fue premiada con la primera mención en el concurso de cuentos de Casa de las Américas.

Sin duda, lo sé mejor que nadie, estas alegrías son siempre incómodas, demasiado "sociales" y en el fondo no sirven. De todos modos, es lo que quise, lo que yo mismo buscaba, un acceso, un puente a la "literatura" entendida como un territorio distante de la escritura. Digamos que soy dos personas, el que escribe y el que espera publicar. [...] Esa confirmación (el telegrama que llega a las ocho de la mañana anunciando que uno ha sido "mencionado" en el mundo de la literatura) la esperaba incluso antes de haber escrito el libro (2015: 291).

Es como si Piglia dijera: lo hice todo para ganar un premio literario, pero ahora que he ganado me permito dudar del "mundo de la literatura". Al menos en esa dirección parecen pedir ser leídos los tres tomos (y aquí retomo el tema de cómo se crea el mito de escritor), en los que se acumulan las escenas iniciáticas del ingreso del niño pequeño, que lee sin saber leer, en la literatura. A fines de los años setenta, en plena dictadura, Piglia comienza a convertirse en un escritor conocido. Del intelectual semi-secreto, cuyo prestigio lo mantenía relativamente oculto o protegido en trabajos editoriales, revistas, traducciones, grupos de estudio de la época, pasa a ser, poco a poco, una figura algo más pública. Una exposición que, sin embargo, no tuvo excesos porque nunca abandonó los medios tonos ni explotó la celebridad. Quisiera volver a ese momento. En la entrada del miércoles 11 (¿de abril?) de 1979, comenta un reportaje que le han hecho, para el cual debe sacarse unas fotos que acompañen la nota. Y dice: "Ayer, fotos en una plaza. Me 
"disfrazo" con mi piloto de detective para soportar las imágenes. Hay que vivir en tercera persona" (2017: 95). El escritor es siempre -para Piglia- un ser secreto que, al hacerse público, necesita un "disfraz", una puesta en escena (literaria también, a través de la figura del detective), algo que lo vele, lo oculte, para hacerse presente ante la institución ${ }^{5}$. No hay en los diarios muchas escenas con fotos, las imágenes, en general, ceden ante las citas, la palabra. Sin embargo, se hace mención a algunas fotos personales años antes, por ejemplo, en una escena que relata el viernes 10 de marzo de 1967. Allí cuenta que recibió las fotos que le sacó el fotógrafo de Primera Plana para una entrevista: "Voy a usar una de ésas en el libro. Piri se sorprendió porque me corté el pelo muy corto antes de sacarme esas fotos. "Quiero parecer cualquier cosa menos un escritor", le dije" (2015: 295-296). Es mucho más joven, candidato a estrella en ascenso después del premio cubano, pero su identidad ya es un problema. La identidad de escritor es un disfraz, pero también la ficción lo es: "Lo que va de De Quincey a Capote es lo que va de mi novela a las grabaciones verdaderas de Los hijos de Sánchez de Oscar Lewis. Frente a la non-fiction, frente a la novela-reportaje, la que imagino sería una novela "disfrazada" de ficción verdadera" (2015: 283). Y esta declaración parece ser la descripción de la novela que nunca escribió bajo ese género, pero que puede leerse en los Diarios.

La política del disfraz es la táctica ingenua y divertida que rápidamente encuentra su formulación teórica: "hay que vivir en tercera persona". La frase, como sabemos, tiene un efecto evidente, obvio, sobre lo que estamos leyendo (la escritura de los diarios, editada, atribuida al personaje de Emilio Renzi). La declaración "hay que vivir en tercera persona" es en verdad una cita de Bertold Brecht (autor sobre el que está preparando unos cursos en ese momento), como lo aclara en una anotación del 3 de noviembre de 1980:

Sólo podemos nombrar las cosas que les ocurren a otras personas, nuestra propia experiencia vivida, nuestra existencia, nuestra sensación del paso del tiempo están demasiado próximas a nosotros como para ser visibles de un modo externo (de ahí la imposibilidad y fascinación de los diarios personales como éste) [...]. De allí la premisa de Brecht, vivir en tercera persona (2017: 131).

19 La escritura adopta un carácter utópico que lo lleva a plantear, en la entrada del $17 \mathrm{de}$ julio de ese año, la ilusión de escribir "Una autobiografía teórica. La historia de los pensamientos de un hombre, de sus lecturas comentadas. Una vida ejemplar" (2017: 118). O a plantear, más radicalmente, un texto conceptual, enteramente despojado de materia, de argumentos, de acontecimientos: el "Libro de escritor que tiene ciertas ideas; en realidad, lo mejor sería escribir un libro que tuviera la forma de un diario teórico" (2017: 120). O, siguiendo con las ficciones de escritura: "Quizás una parte (la tercera parte) del ensayo podría ser un diario del pensar, que combinara ideas todavía no pensadas, o ideas a punto de ser pensadas, o ideas que solo se pueden pensar al escribir" (2017: 121). Algo de lo que leemos en los Diarios tiene este formato impreciso, en relación con una conceptualización más abstracta.

La figura del agente doble, del encubierto, se fragua para Piglia precisamente en los años tempranos, cuando se imagina a sí mismo como un simulador. Pero ese agente encubierto no es sino el efecto de la "clandestinidad". Los diarios comienzan a ser escritos cuando Piglia tiene 16 años, en 1957, y la familia debe dejar la casa de Adrogué. El padre, peronista, ha salido de prisión hace poco y decide irse a Mar del Plata; su madre lo acompaña. El joven debe abandonar todo y en la "casa desmantelada" comienza a llenar esos 327 cuadernos $^{6}$. La experiencia de la clandestinidad es una experiencia política central en la segunda mitad del siglo XX en Argentina. En esa experiencia de la 
clandestinidad confluyen en él política, experiencia personal y literatura. Aunque Renzi y el autor mencionen la palabra exilio, lo que se impone es lo clandestino. Se impone la doble vida del rechazado que no tiene otro camino que la conspiración porque no puede operar en ningún sitio concreto (ni en el partido, ni en la organización y, por supuesto, tampoco en el poder). No se trata del revolucionario, que salta a la acción. El conspirador es algo menos articulado políticamente, está y no está en el sistema, y se siente amenazado por todos lados. Tiene ideas, pero debe ocultarlas; tiene métodos, pero no puede develarlos, tiene un nombre, pero debe usar otro. Vive una vida a contrario. Esta figura atraviesa los tres volúmenes del diario a través de varios personajes: su padre, los escritores, los sindicalistas, los peronistas, los anarquistas, los miembros de las guerrillas urbanas, los ladrones. Y podemos agregar que no hay moral en esas vidas clandestinas, tanto su amigo Cacho -un ladrón- como su amigo Elías -un revolucionario- sufren la misma segregación en tanto conspiradores: el primero va a la cárcel, el segundo vive en la clandestinidad. Las relaciones de Emilio Renzi/Piglia están contadas a través de contactos, encuentros secretos, nombres falsos, identidades que nunca se develan.

Esta figura se hace fuerte en Piglia precisamente durante los años sesenta. Uno de los tópicos más frecuentados por la historiografía en ese periodo es el de la relación entre intelectuales y política. Fueron los años en que, bajo el efecto de la revolución cubana en 1959, una politización generalizada del campo intelectual y un giro hacia la izquierda se volvieron recurrentes. El punto de inflexión fue siempre la redefinición de las prácticas estéticas y culturales con el nuevo escenario político revolucionario y el nuevo lugar que ocupaban los medios, con el reconocimiento del poder de las masas y la necesidad de romper definitivamente la tradicional división entre cultura letrada y popular/masiva para desarrollar una cultura revolucionaria y emancipatoria. La figura del revolucionario se volvió un valor de primer orden y la revolución fue una meta de la política radicalizada. Paralelamente, la "autoconciencia" (en arte y política) se volvió no sólo un valor agregado de las obras sino una suerte de imperativo del arte revolucionario.

Mientras la práctica revolucionaria se afianzaba, varios escritores intentaron definir los paralelismos entre la política y la estética. El caso de Cortázar es quizás el más emblemático: para él, la revolución en el arte obedece a la libertad del artista, las obras deben ser estéticamente revolucionarias, no deben apostar a una política concreta. Esa fue la versión hegemónica que parecía haber zanjado la cuestión durante los años sesenta: si un cuento, "Apocalipsis en Solentiname", por ejemplo, usaba procedimientos literarios sofisticados, acompañaba sin dificultad la militancia de izquierda de su autor, aunque éste viviera en París y fuera traductor de Naciones Unidas. Pero también existieron otras posibilidades, que no resolvían el "dilema" entre estética y política, sino que lo ponían en escena como el gran problema del arte y la literatura, un compromiso pensado en términos de práctica estética. Este aspecto creo que lo despliegan los Diarios. Si bien la ficción de Piglia trabaja también en esa dirección, los Diarios la explicitan. Muchas escenas recogen esta preocupación.

23 A fines de 1965, Sergio Camarda, cercano al Ejército Guerrillero del Pueblo, convoca a Piglia para que dirija una revista cultural revolucionaria, Literatura y Sociedad, de la que sale un único número. Ambos tienen ideas diferentes sobre la intervención del intelectual en política y la relación se vuelve conflictiva, pero logran hacer el primer número. En la entrada del jueves 20 de mayo de 1965, Renzi anota:

Lo divertido de la tarde fue el descubrimiento de que Sergio tiene varias armas en su casa. Abrimos un baúl para buscar unas fotografías, pero en realidad sólo 
encontramos armas. "Son de un amigo", dijo Sergio, pero yo no le creí. No es difícil encontrar una relación entre estas armas y el financiamiento de la revista. Algo lejanamente ligado al dinero de los cubanos (creo) (2015: 187).

Horacio, mi primo, con noticias sobre Cacho, apareció la alternativa de volver al departamento allanado y vivir ahí, hasta que salga. Ocupar el aguantadero descubierto sería un modo de estar en peligro, siempre atento a los movimientos exteriores" (2015: 232). Sospechando que la policía puede ir a buscarlo por sus conexiones políticas, Renzi/ Piglia busca refugio en la casa de un amigo que está preso por robo, como si se escondiera a la vista de quien lo busca, protegiéndose dentro del peligro. A medida que el clima represivo arrecia en la Argentina, la convicción de la clandestinidad se hace más fuerte: "En todo escritor se esconde en potencia un terrorista. Ejemplo, Roberto Arlt. Un terrorista porque no puede nunca escapar al sentimiento de ilegitimidad, de vida clandestina, de hombre perseguido" (2015: 237). Pero no se trata solamente de las fuerzas represivas, la situación de complot abarca todos los ámbitos de la vida: "Jorge Álvarez parece entusiasmado con los cuentos. La semana que viene se va a constituir un "tribunal" presidido por Walsh para juzgarlos. Me gusta esa metáfora porque veladamente alude a la peligrosidad literaria que me gustaría que tuvieran mis escritos" (2015: 285). Aunque, sin duda, es la experiencia de la política la que marca a fuego al escritor respecto de la exterioridad al sistema: "Desde siempre hemos desconfiado de la policía y siempre nos hemos considerado infractores de la ley (no importa cuál), de modo que cualquier cruce con alguien uniformado se convierte en una escena compleja" (2015: 326). Ya se hable de un lugar donde vivir, de cómo escribir o mandar un cuento a una editorial, de cómo leer o ser leído, una relación "transparente" es imposible; siempre habrá una desconfianza radical entre el mundo de la literatura y el del escritor. Y esto llega a involucrar de manera directa a los escritores de su generación: "En muchos casos, el recurso a la literatura como salida o como salvación es efecto de la crisis de la izquierda, o del comienzo de la madurez. Enfrentados con el escepticismo, piensan que esa mirada desencantada los convierte de hecho en escritores" (2015: 298). Ser escritor es ocupar cualquiera de esas casillas.

\section{Final}

Desde los años veinte, y aún antes, desde la Revolución de Octubre, la vanguardia se constituyó no sólo como una nueva práctica estética sino también como un espacio para debatir el lugar del arte y la literatura en lo público, la autonomía estética, las identidades intelectuales y sus articulaciones con la política. Esa relación sofisticada no dejó de ser problemática. Walter Benjamin identificó tempranamente el problema cuando escribió: "[...] los Surrealistas confunden constantemente el no-conformismo moral con la revolución proletaria [...]" (2003: a1,2, mi traducción) ${ }^{7}$. Visualizó, de este modo y tempranamente, una flexión particular de la relación: habría una confusión entre la estética y la política que hace crisis en momentos de radicalización (del arte o de la

Cuadernos LIRICO, Hors-série | 2019 
política), pero que revela la tensión latente desde que la autonomía estética comienza a establecerse durante el régimen moderno del arte. La articulación del arte con la política, precisamente por su carácter no "natural", requirió de un discurso que permitiera hablar de las condiciones de posibilidad de esa relación.

Los diarios de Emilio Renzi parecen ser, en su multiplicidad, una forma de rondar un problema que desde siempre estuvo claro: lo más amado, la literatura, se ha convertido, a mitad de siglo y en el contexto argentino, en una zona de confort. La voluntad de removerla, transformarla, fue el disparador de la literatura de Manuel Puig, Juan José Saer, Osvaldo Lamborghini. Fue el disparador también de Piglia, que empeñó el conjunto de su escritura en llevar adelante su cuestionamiento y reemplazar el confort por la incomodidad.

\section{BIBLIOGRAFÍA}

Benjamin Walter, The Arcades Project, Cambridge, Mass., Harvard University Press, 2003.

Translated by Howard Eiland and Kevin McLaughlin. Prepared on the basis of the German volume edited by Rolf Tiedemann.

Huyssen Andreas, Después de la gran división. Modernismo, cultura de masas, posmodernismo, Buenos Aires, Adriana Hidalgo, 2002.

Lamborghini Osvaldo, Novelas y cuentos, Barcelona, Ediciones del Serbal, 1988.

Piglia Ricardo, Teoría del complot, Buenos Aires, Mate, 2007.

--- El último lector, Buenos Aires, Anagrama, 2005.

--- Los diarios de Emilio Renzi. Años de formación, Barcelona, Anagrama, 2015.

--- Los diarios de Emilio Renzi. Los años felices, Barcelona, Anagrama, 2016.

--- Los diarios de Emilio Renzi. Un día en la vida, Barcelona, Anagrama, 2017.

Rodríguez Pérsico Adriana, "Los diarios de Emilio Renzi o el pudor autobiográfico", Zama. Revista del Instituto de Literatura Hispanoamericana $\mathrm{n}^{\circ}$ 9, año 9, Universidad de Buenos Aires, 2017, p. 59-69, Web.

\section{NOTAS}

1. La frase está en Sebregondi se excede (Novelas y cuentos, 1988).

2. Como sostiene Adriana Rodríguez-Pérsico, “[...] la actividad del diarista revela una tenaz política intervencionista al punto que en la versión final es difícil distinguir fechas de composición" (2017 Web).

3. Baste recordar la dimensión de esos libros, fundadores de mitologías, de personajes, de interpretaciones, que se imponían tanto por su dimensión simbólica como material. 
4. Lo que Andreas Huyssen llamó "la gran división" (2002) -siguiendo críticamente la reflexión de la Escuela de Frankfurt- fue la aparición de la cultura de masas, la que obligó a reconfigurar los diferentes ámbitos de la producción cultural.

5. Un excurso: el impermeable es la prenda-disfraz por excelencia; a lo largo de los diarios, cuando alguien se pone un impermeable es para desaparecer, hacerse pasar por otro, simular.

6. Piglia cuenta ampliamente esta escena inicial en los diarios. Y lo hace al público en el documental que Andrés Di Tella filma sobre los momentos de revisión de los diarios, 327 Cuadernos (2015).

7. “ $[\ldots]$ the Surrealists constantly confuse moral nonconformism with proletarian revolution [... ]"(2003: a1,2).

\section{RESÚMENES}

El propósito de este trabajo es explorar la conformación de una nueva idea de literatura en la cultura latinoamericana de los años setenta tomando como material primario los tres volúmenes de Los diarios de Emilio Renzi de Ricardo Piglia. La literatura fue una práctica ligada a la tradición elitista pero aún estaba cargada de promesas emancipatorias y fue repolitizada por los jóvenes del post-boom. Piglia tuvo un lugar central en esa redefinición. La edición de sus diarios muestra la exploración del propio Piglia sobre las nuevas posibilidades de la literatura, sobre las ideas de obra, autor, vanguardia. Se interrogan por la práctica de la literatura en el momento en que se está produciendo un cambio radical en su concepción.

Cet article explore la configuration d'une nouvelle idée de littérature apparue au sein de la culture latinoaméricaine des années soixante-dix, à partir de l'édition en trois volumes de Los diarios de Emilio Renzi de Ricardo Piglia. Bien que encore liée à une tradition élitiste, la littérature était une pratique pleine de promesses d'émancipation, et elle fut nouvellement chargée de sens politique par les jeunes écrivains du post-boom. Piglia détient une place centrale dans cette redéfinition. La publication de ses journaux met en relief son exploration de nouvelles possibilités autour des idées d'oeuvre littéraire, auteur, avant-garde. Les journaux interrogen la pratique littéraire au moment même où un changement radical des idées la concernant est en train de se produire.

This article explores the constitution of a new idea of literature in the Latin American culture during the seventies. The primary sources will be the three volumes of Los diarios de Emilio Renzi by Ricardo Piglia. Literature was a practice related to lettered tradition but it was also an emancipatory promise re-politicized by the young post-boom writers. Piglia was in the center of that redefinition. The publication of his diaries shows Piglia's exploration of the new possibilities of literature, the ideas of literary work, author, Avant-garde. His diaries question the idea of literature at the moment when a radical change is coming. 
ÍNDICE

Palabras claves: Piglia, literatura, obra, autor, años setenta

Keywords: Piglia, literature, literary work, author, the seventies

Mots-clés: Piglia, littérature, oeuvre, auteur, années soixante-dix

\section{AUTOR}

GRACIELA MONTALDO

Columbia University

gm2168@columbia.edu 